\title{
ADSORPTION OF VAPORS BY SILICA GELS OF DIFFERENT STRUCTURES
}

\author{
F. E. Bartell and John E. Bower \\ Department of Chemistry, University of Michigan, Ann Arbor, Michigan \\ Received November 19, 1951 \\ INTRODUCTION
}

The use of the Gibbs adsorption equation for the evaluation of free surface energy changes that occur during adsorption of vapors had until recently been applied rigorously only to nonporous solids. This method has now been extended $(1,2)$ to apply to the case of porous adsorbents and, moreover, it has been shown how it should be possible to determine the specific surface areas of porous adsorbents from free energy considerations. To test further the general validity of this method, a study has been made in the present research of porous adsorbents (silica gels) which differed from each other in pore radius, pore volume, and in surface area but which were of the same chemical character. These silica gels were used with a series of adsorbate liquids with properties which, it was believed, would cause them to give quite different interaction energies with a given adsorbent. It was found that the free surface energy changes which occurred when unit area of the clean porous solid surface was replaced by a unit area of solid-liquid or solid-saturated vapor interface were independent of the precise structure and of the apparent density of the solid.

\section{EXPERIMENTAL}

\section{Materials}

Liquids selected as adsorbates formed zero contact angles with silica, they had a fairly large range of surface tension values, were such as should give a fairly wide range of energy changes on contact with a siliceous surface, and each liquid had an appreciable vapor pressure at room temperature. These liquids were water, methyl alcohol, ethyl alcohol, n-propyl alcohol, benzene, hexane, and carbon tetrachloride. Each organic liquid received final purification by fractionation and by vigorous dehydration. The water was re-distilled from an alkaline permanganate solution. Each liquid was sealed under vacuum into its sample tube after having been de-aerated by a freezing process. 
Three quite different silica gels were procured and are referred to as Gels No. 1, No. 2, and No. 3. Gels No. 1 and No. 3 were prepared by the hydrolysis of silicon tetrachloride. Gel No. 1 was identical with that described and employed by Bartell and Dobay (3) and gel No. 3 was identical with that employed by Bartell and Donahue (4). Gel No. 2 was a commercial product which had been prepared from sodium silicate. It was purified by refluxing with nitric acid and repeated flushing with distilled water. The specific surface area of each gel was determined by the BET nitrogen adsorption method, using $16.2 \mathrm{~A} .^{2}$ as the molecular area of nitrogen. At least three separate determinations were made for each gel. The pore volume of each gel was estimated from the apparent density as determined by mercury displacement. Gels No. 1, No. 2, and No. 3 were found to have BET specific surface areas $(a)$ of 320,355 , and $455 \mathrm{~m} .{ }^{2} / \mathrm{g}$., respectively, and pore volumes $(V p)$ of $1.16,0.43$, and $1.01 \mathrm{cc} . \mathrm{g}$., respectively.

\section{Apparatus}

The apparatus and techniques used to determine the low-temperature nitrogen adsorption isotherm data from which the specific surface areas were calculated were the same as those described by Emmett (5) and by Bartell and Dodd (6). A nitrogen vapor pressure thermometer was used to obtain the temperature of the liquid air bath and to give directly the saturation vapor pressure of nitrogen at that temperature.

The data for the isothermals for the adsorption of the various organic liquids and of water on the silica gels were obtained gravimetrically by means of McBain-Bakr quartz spiral balances (7). The gravimetric apparatus and specialized techniques were very similar to those described by Bartell and Dobay (3).

The vapor pressure was controlled by precise control of the temperature of the liquid adsorbate sample. Multiple adsorbent tubes made possible the simultaneous determination either of isotherms of a given liquid on different samples of the same gel or of isotherms of a given liquid on different gels.

The adsorption data obtained for each of the three gels are presented graphically in Figs. 1 and 2.

In all cases the weights adsorbed per gram of gel $(x / m)$ are numerical averages of at least two independent determinations. The accuracy of the data in the high pressure range depends primarily upon the temperature control of the liquid adsorbate, i.e., any inaccuracy will be principally in the abscissa $\left(p / p^{0}\right)$. In the low pressure range any inaccuracy will be principally in the ordinate $(x / m)$. 


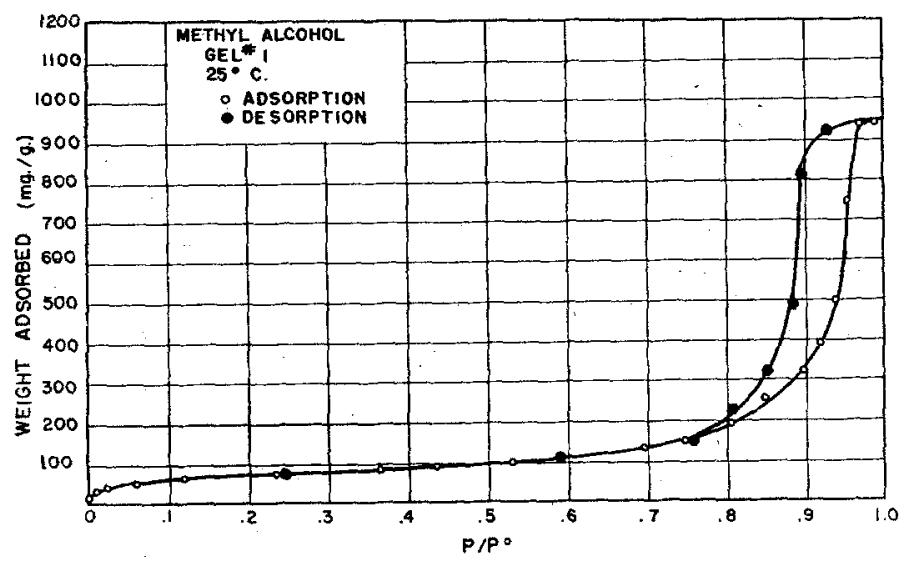

A

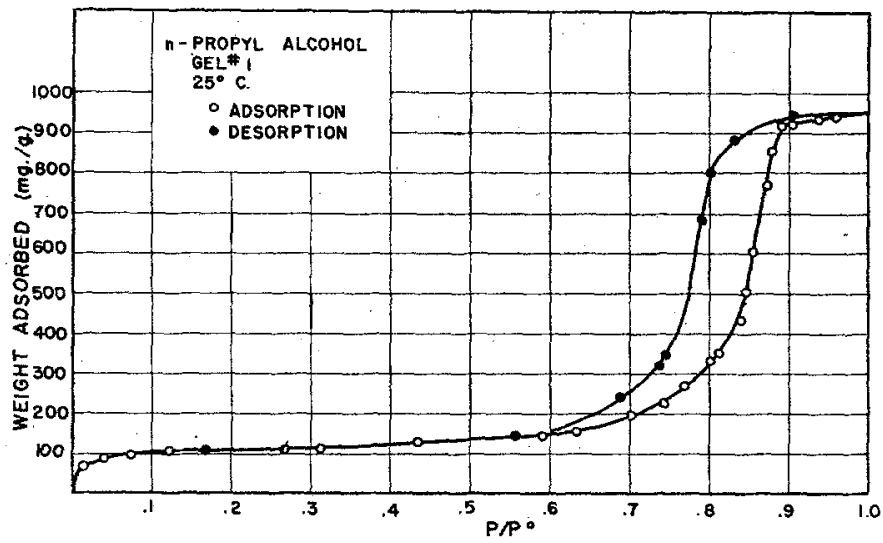

B

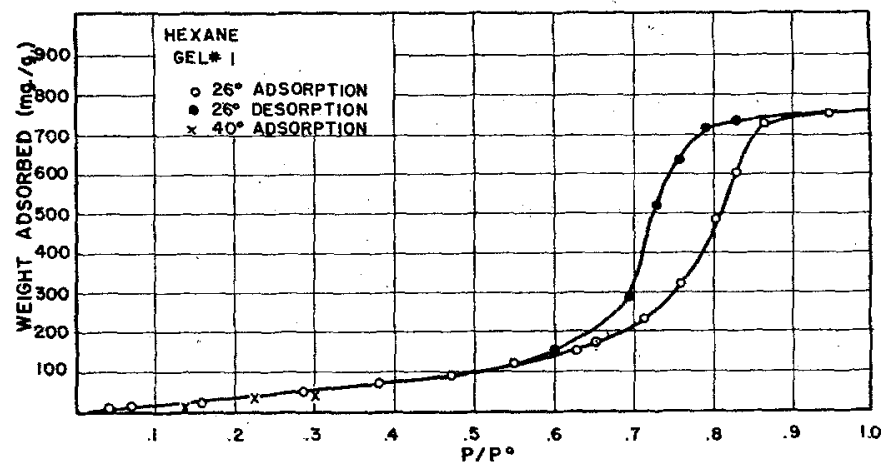

C 


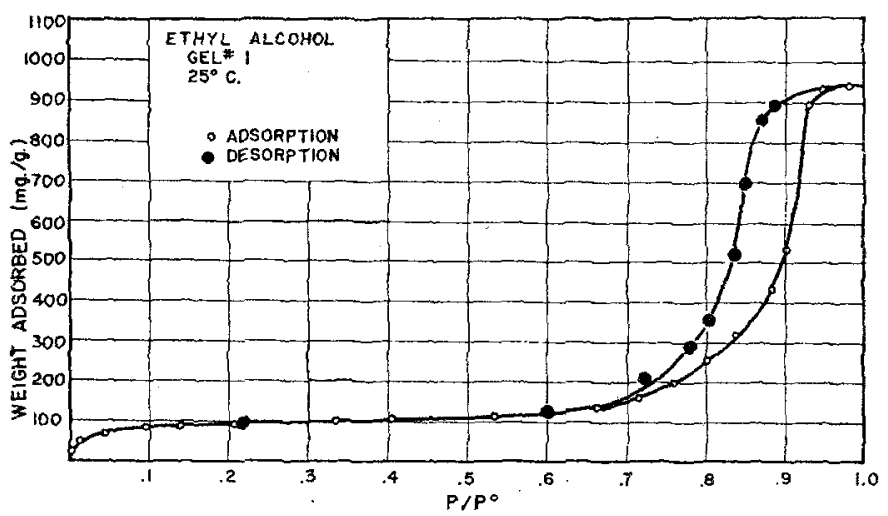

$\mathrm{D}$

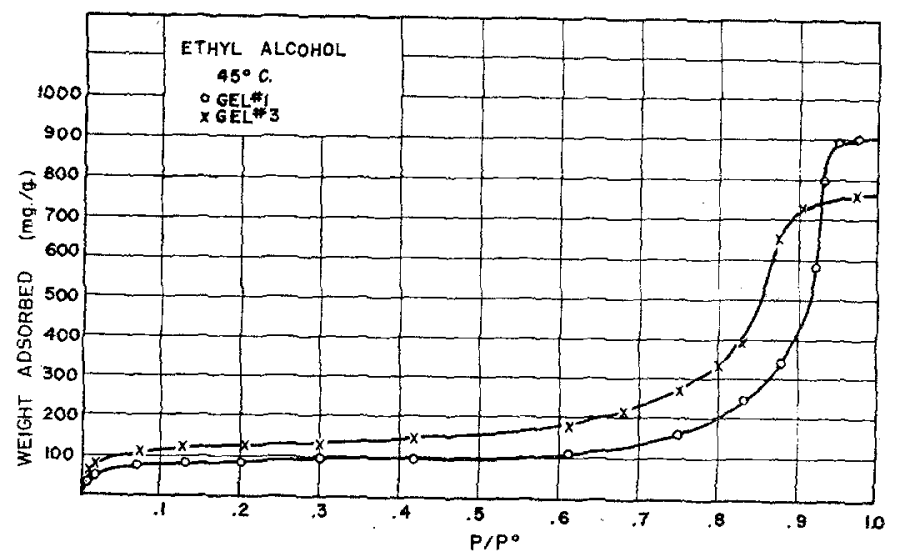

E

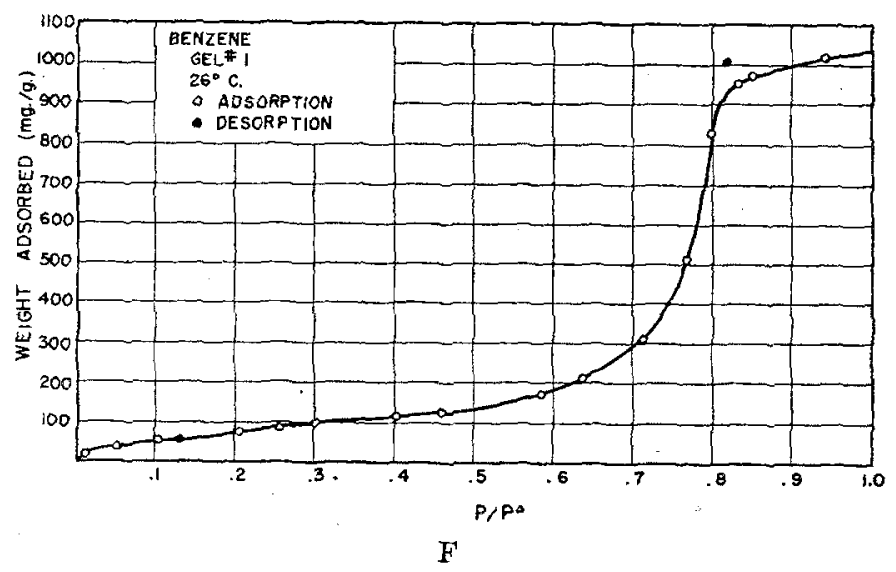

FIG. 1. Adsorption isotherms. Different organic liquids on silica gel. 


\section{Theoretical}

The use of the Gibbs adsorption equation as an indirect method of determining free surface energy changes occuring during adsorption was first proposed by Bangham and Razouk $(8,9,10)$. Details of the procedure and formulations usually employed may be found in the papers of Boyd and Livingston (11) and of Harkins and Jura (12).

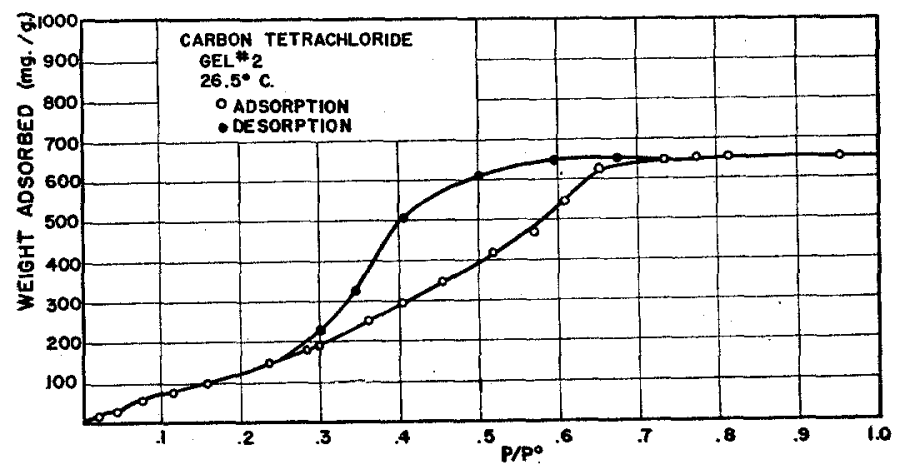

A

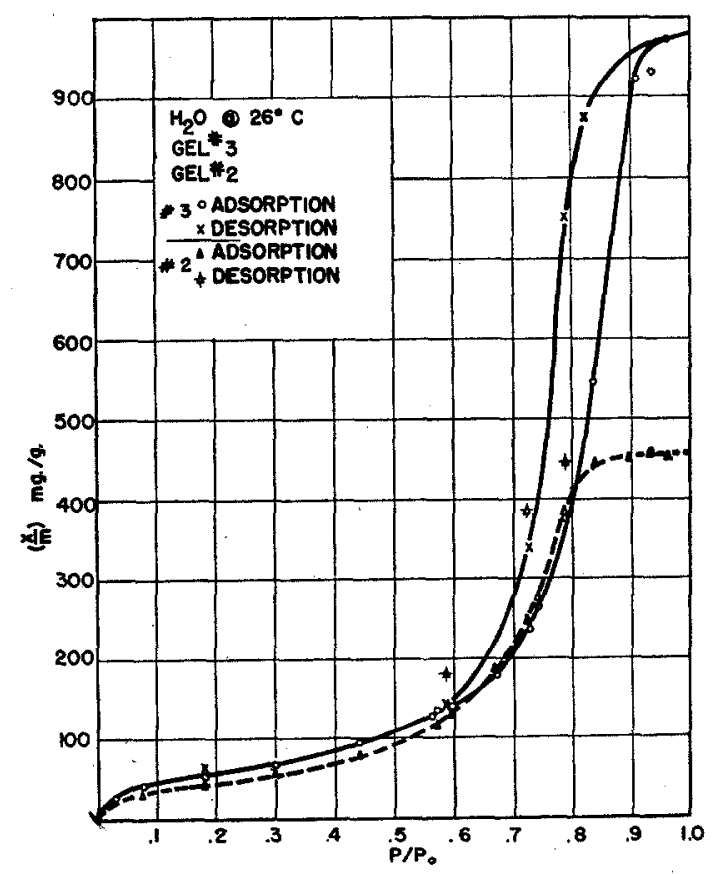

B 


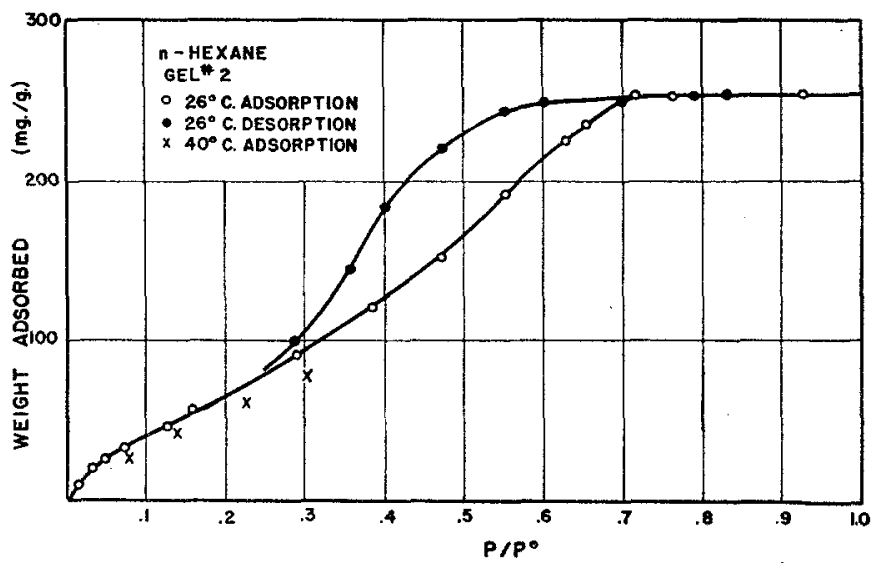

C

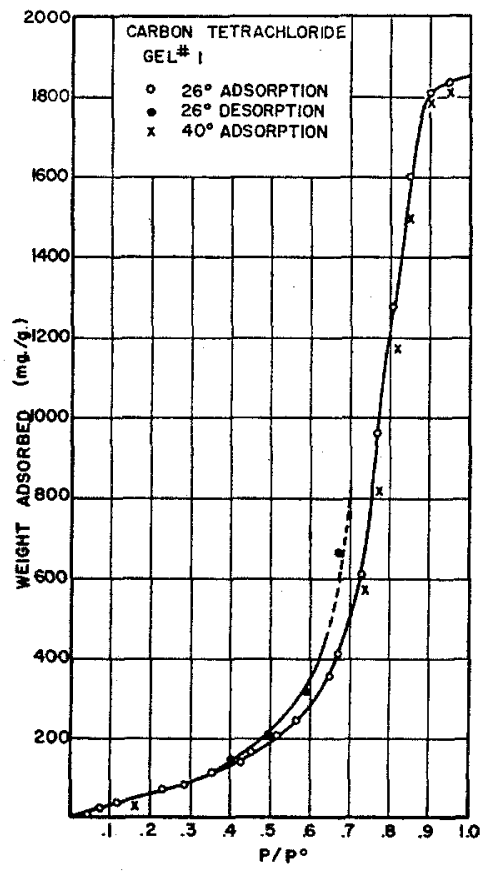

D

FIG. 2. Adsorption isotherms. Different liquids on silica gel.

Recently Dobay, Fu, and Bartell (1) and Fu and Bartell (2) have shown that for adsorption by porous adsorbents the methods and formulations of the theory must be modified somewhat. The lowering of the free surface energy $\phi$ at $P / P^{0}=1$ was demonstrated to be equal to the adhesion tension $(A)$ of the liquid adsorbate against the solid (defined by 
the equation $\left(\gamma_{S_{0}}-\gamma_{S L}\right)$. By employing the Gibbs equation the following formulation was developed:

$$
\phi_{S}=A=\left(\gamma_{S 0}-\gamma_{S L}\right)=\frac{R T}{M a} \int_{P / P_{0}=0}^{P / P_{0}=1} \frac{x}{m} d \ln P / P_{0}
$$

With the use of equation [1] the work of spreading, $W_{S}$, (or the "initial spreading coefficient," $\gamma_{S_{0}}-\gamma_{S L}-\gamma_{L V}{ }^{0}$ ) and the work of adhesion $W a$ (or $\gamma_{S_{0}}+\gamma_{L V^{0}}-\gamma_{S L}$ ) can be evaluated for liquids which form no angle of contact. The total free surface energy lowering which occurs when the adsorption by a porous solid is carried to saturation pressure is visualized as being composed of two terms: first, that representing the replacement of the clean solid surface by a solid-liquid and a liquid-vapor interface, and second, that representing the destruction of the liquid-vapor interface due to further "adsorption" and filling of the capillaries.with liquid. The calculations are simplified by employment of a hypothetical process whose end states are identical with those of the actual process (1). The total free energy lowering at saturation may then be written as:

$$
\begin{aligned}
\phi_{S}=\frac{R T}{M a} \int_{P / P_{0}=0}^{P / P_{0}=\left(P / P_{0}\right) b} \frac{x}{m} d & \ln P / P_{0} \\
+ & \frac{R T}{M a} \int_{P / P_{0}=\left(P / P_{0}\right) b}^{P / P_{0}=1} \frac{x}{m} d \ln P / P_{0},
\end{aligned}
$$

where $\left(P / P^{0}\right)_{b}$ represents that reduced pressure (less than $P / P^{0}=1$ ) at which a liquid film has been formed. The first term in equation (2) is interpreted to represent the energy change $\left(\gamma_{S_{0}}-\gamma_{S L}-\gamma_{L V}{ }^{0}\right)$ which is equal to $\left(\gamma_{S_{0}}-\gamma_{S V^{0}}\right)$ if $\theta=0^{0}$. $\uparrow$ The second term represents the destruction of unit area of liquid surface and should therefore be equal to $\gamma_{L V^{0}}$. A graph of $\phi$ vs. $P / P^{0}$ reveals the composite nature of the total free energy changes, $\phi_{S}$, and permits the individual quantities $\phi=\left(\gamma_{S_{0}}-\gamma_{S V^{0}}\right)$, $\phi_{S}=\left(\gamma_{S_{0}}-\gamma_{S L}\right)$ and $\gamma_{L V}{ }^{0}$ to be evaluated. That is:

$$
\phi_{S}-\phi_{b}=\gamma_{L \nabla^{0}} \text {. }
$$

It was found (2) that a plot of $\log \phi$ vs. $\log P / P^{0}$ permitted the intersection point to be more accurately determined.

* The following symbols are employed: $\gamma=$ any surface tension, interfacial tension, or free surface energy. Subscripts $S_{0}, S L, S V^{0}$ represent solid-vacuum, solid-liquid, and solid-saturated vapor interfaces, respectively. Adhesion tension $(A)$ is defined as $\left(\gamma_{S_{0}}-\right.$ $\left.\gamma_{S L}\right)$. Spreading coefficient is defined as $\left(\gamma_{S_{0}}-\gamma_{S L}-\gamma_{L V}{ }^{0}\right) \cdot \phi=$ lowering of free surface energy per $\mathrm{cm} .{ }^{2}$ of solid. $\phi_{S}$ represents the lowering of free surface energy per $\mathrm{cm}^{2}$ at $P / P^{0}=1$. $\phi_{b}$ represents the lowering of free surface energy per cm. ${ }^{2}$ at $\left(P / P^{0}\right) b . x / m=$ weight of vapor adsorbed per gram of gel. $M=$ molecular weight of adsorbate. $a=$ specific surface area.

$\dagger$ Also according to Young's equation $\left(\gamma_{S V_{0}}-\gamma_{S L}\right)=\gamma_{L V}{ }^{0} \cos \theta$. 
If the surface area is unknown and is to be determined then equation [2] may be written

$$
\begin{gathered}
a \phi_{S}=\frac{R T}{M} \int_{P / P_{0}=0}^{P / P_{0}=\left(P / P_{0}\right)_{b}} \frac{x}{m} d \ln P / P_{0} \\
\quad+\frac{R T}{M} \int_{P / P_{0}=\left(P / P_{0}\right)_{b}}^{P / P_{0}=1} \frac{x}{m} d \ln P / P_{0} \\
a \phi_{S}=a \phi_{b}+a \gamma_{L V^{0}} \\
\frac{a \phi_{S}-a \phi_{b}}{\gamma_{L V^{0}}}=a .
\end{gathered}
$$

That the energy change $\left(\phi_{b}\right)$ corresponding to $\left(\gamma_{S_{0}}-\gamma_{S V^{0}}\right)$ should occur at some pressure less than the saturation pressure $\left(P^{0}\right)$ during adsorption by a porous solid is to be expected since in small capillaries liquid and vapor are at equilibrium at pressures much lower than the saturation pressure of bulk liquid at that temperature (Kelvin equation).

\section{Free Surface Enèrgy Changes}

\section{The Adhesion Tension, Spreading Coefficient and Work of Adhesion}

Employing the equations discussed above the quantity $a \phi$ was determined by graphical integration. Graphs of $\log a \phi$ versus $\log P / P^{0}$ are shown in Fig. 3. The plots seem to indicate quite clearly that two disparate phenomena occur consecutively. The value of $a \phi$ at the intersection point corresponds to the energy change $a\left(\gamma_{S_{0}}-\gamma_{S L}-\gamma_{L V}{ }^{0}\right)$, which is equivalent to $a\left(\gamma_{S_{0}}-\gamma_{S V^{0}}\right)$ if there is no angle of contact. The intersection point represents that reduced pressure at which a film of sufficient thickness has formed in the "average" capillary so that capillary condensation can begin.

The value of $(a \phi)$ at $P / P^{0}=1$ represents $a\left(\gamma_{S_{0}}-\gamma_{S L}\right)$ or $a A$. Dividing this value by the previously determined BET specific surface area gave the value of the adhesion tension, and by subtracting $\gamma_{L V}{ }^{0}$, the initial spreading coefficient recorded in columns 4 and 5 of Table I. In column 6 are recorded the values for the work of adhesion $\left(\gamma_{S_{0}}-\gamma_{S L}\right.$ $\left.+\gamma_{L V}{ }^{0}\right)=A+\gamma_{L V}{ }^{0}$.

Although gels No. 1, No. 2 and No. 3 differed in method of preparation, in pore radii, and in pore volume, and although the isothermals were strikingly different in shape, the values of the adhesion tensions and of the spreading coefficients calculated for the same adsorbate on the different gels were in fairly good agreement. It may be concluded, therefore, that the siliceous surfaces must be quite similar in nature, differing only in specific surface area. The relative order of the energy changes meas- 

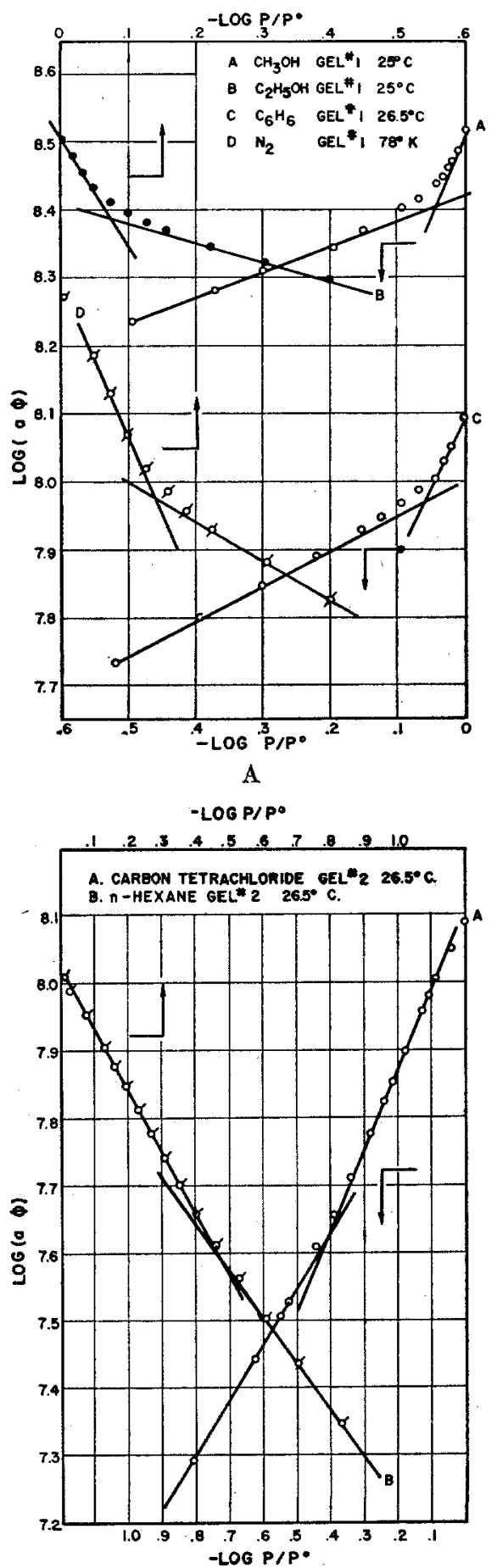


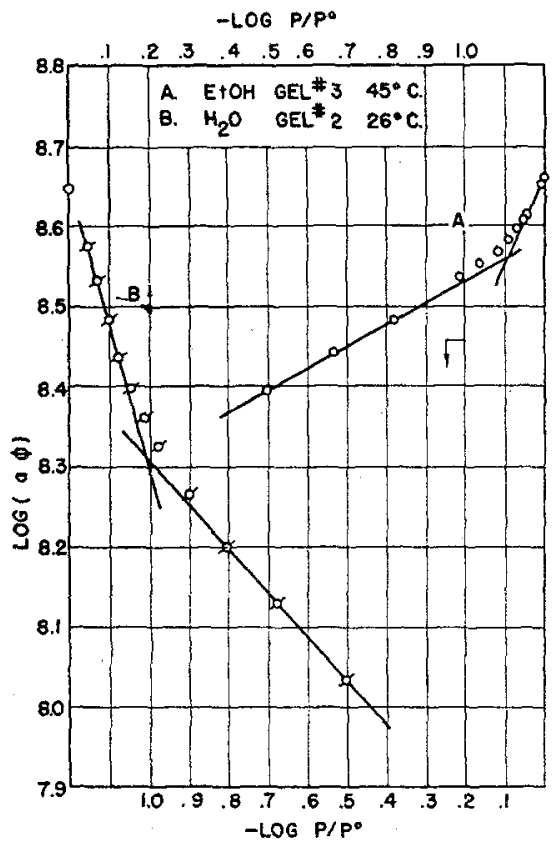

$\mathrm{C}$

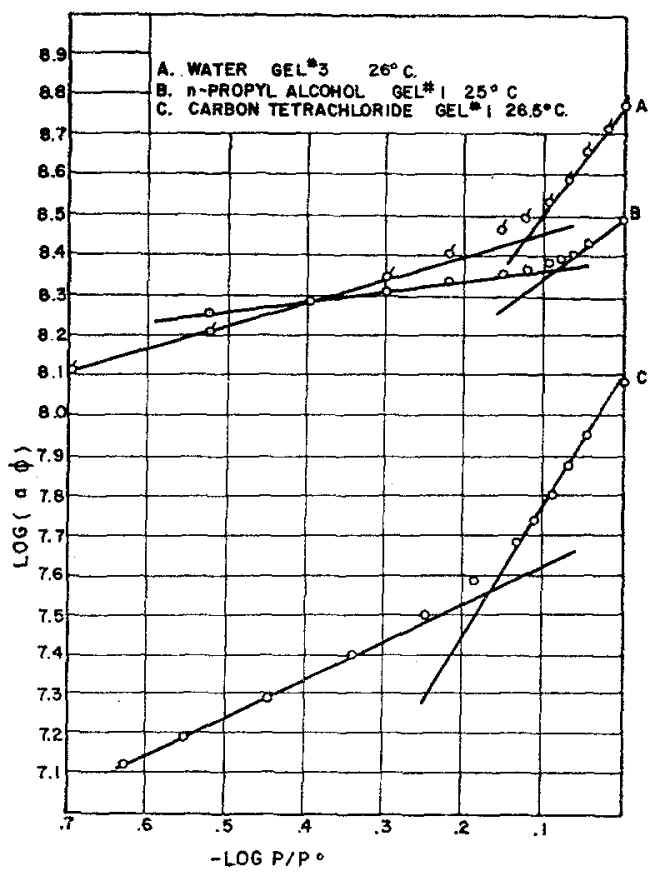

$\mathrm{D}$

Fig. 3. Free surface energy changes as related to relative pressures. $\log (a \phi)$ vs. $\log P / P^{0}$. 
TABLE I

Free Surface Energy Changes

\begin{tabular}{|c|c|c|c|c|c|}
\hline & & ${ }^{\circ} \mathrm{C}$ & ergs/em. ${ }^{2}$ & $\mathrm{ergs} / \mathrm{cm} .^{2}$ & ergs $/ \mathrm{cm} .^{2}$ \\
\hline \multirow{10}{*}{ Gel No. 1} & $\mathrm{CH}_{3} \mathrm{OH}$ & 25 & 102.7 & 79.7 & 124.9 \\
\hline & $\mathrm{C}_{2} \mathrm{H}_{5} \mathrm{OH}$ & 25 & 99.9 & 76.9 & 122.2 \\
\hline & $\mathrm{C}_{2} \mathrm{H}_{5} \mathrm{OH}$ & 45 & 97.5 & 76.7 & 117.3 \\
\hline & $n-\mathrm{C}_{3} \mathrm{H}_{7} \mathrm{OH}$ & 25 & 97.1 & 73.3 & 120.5 \\
\hline & $\mathrm{C}_{6} \mathrm{H}_{6}$ & 26.5 & 58.6 & 29.7 & 86.9 \\
\hline & $\mathrm{C}_{6} \mathrm{H}_{6}$ & 40 & 54.9 & 26.9 & 81.2 \\
\hline & $\mathrm{CCl}_{4}$ & 26.5 & 38.4 & 11.5 & 64.5 \\
\hline & $\mathrm{CCl}_{4}$ & 40 & 37.7 & 11.8 & 62.1 \\
\hline & $n-\mathrm{C}_{6} \mathrm{H}_{14}$ & 26.5 & 31.0 & 11.7 & 48.8 \\
\hline & $\mathrm{N}_{2}$ & -195 & $(39)^{a}$ & $(29)^{a}$ & $(47.8)$ \\
\hline \multirow[t]{2}{*}{ Gel No. 3} & $\mathrm{C}_{2} \mathrm{H}_{5} \mathrm{OH}$ & 45 & 101.1 & 80.0 & 121.7 \\
\hline & $\mathrm{H}_{2} \mathrm{O}$ & 26 & $(129)^{b}$ & $(61.4)^{b}$ & $(200.8)$ \\
\hline \multirow[t]{3}{*}{ Gel No: 2} & $\mathrm{CCl}_{4}$ & 26.5 & 35.0 & 11.9 & 61.1 \\
\hline & $n-\mathrm{C}_{6} \mathrm{H}_{14}$ & 26.5 & 28.8 & 11.7 & 46.6 \\
\hline & $\mathrm{H}_{2} \mathrm{O}$ & 26 & $(125)^{b}$ & $(57.8)^{b}$ & 196.8 \\
\hline
\end{tabular}

a Insufficient data in very low pressure region for accurate results.

${ }^{b}$ Zero point in doubt, i.e., the isotherm is not reversible in the low pressure region. ing.

- $W c=2 \gamma_{L} v^{0}$ the work of cohesion, and $W a-W c=W s$, which is work of spread-

ured was the same as that which had previously been found for siliceous material by entirely different methods (13-19).

\section{Surface Area}

The specific surface areas of each of the three gels were determined by application of equation [5]. The values so determined for each gel are listed in Table II. The area values calculated using surface tension values of liquids which, varied from 8.8 dynes $/ \mathrm{cm}$. to 72 dynes $/ \mathrm{cm}$. show sufficiently good agreement to attest to the soundness of the method. Calculations of surface area by this method employing adsorption data available in the literature gave equally good results (20).

It may be noted that this method of area evaluation is analogous in theory to the "absolute" method of Harkins (21) for the determination of the surface area of powders.

In the "absolute" method the heat evolved $(H)$ on destroying an adsorbed liquid film which covers the solid is measured calorimetrically. The total enthalpy change is then divided by the surface enthalpy of the liquid per square centimeter $(h)$, where $h=\gamma-T \frac{d \gamma}{d T}$. The area of the liquid film destroyed (equal approximately to the area of the solid) is thus ob- 
tained since $H=a h$. In the Fu and Bartell method, the total free surface energy lowering during destruction of such a liquid film is calculated through the use of Gibbs equation and division of this value by the free surface energy per square centimeter of the liquid (numerically equal to the surface tension) gives the area of the surface destroyed. Thus, Harkins employed total energy considerations and Fu and Bartell free energy considerations.

The values of the specific areas determined by the latter method are seen to be in reasonable agreement with those determined by the BET

TABLE II

Specific Surface Area of Silica Gels No. 1, No. 2, and No. 3 by the Method of Fu and Bartell

\begin{tabular}{|c|c|c|c|}
\hline Adsorbate & $\begin{array}{l}\text { Temperature } \\
{ }^{\circ} \mathrm{C} \text {. }\end{array}$ & $\begin{array}{c}\text { Surface } \\
\text { area } \\
\left(m .^{2} / g .\right)\end{array}$ & \\
\hline \multicolumn{4}{|c|}{ GeL No. 1} \\
\hline $\mathrm{CH}_{3} \mathrm{OH}$ & 25 & 338 & $\begin{array}{r}a=\text { BET nitrogen } \\
\left(320 \mathrm{~m}^{2} / \mathrm{g} .\right)\end{array}$ \\
\hline $\mathrm{C}_{2} \mathrm{H}_{5} \mathrm{OH}$ & 25 & 327 & \\
\hline$n-\mathrm{C}_{3} \mathrm{H}_{7} \mathrm{OH}$ & 25 & 326 & \\
\hline $\mathrm{C}_{2} \mathrm{H}_{5} \mathrm{OH}$ & 25 & 317 & \\
\hline $\mathrm{C}_{6} \mathrm{H}_{6}$ & 26.5 & 329 & \\
\hline$n-\mathrm{C}_{6} \mathrm{H}_{14}$ & 26.5 & 334 & \\
\hline $\mathrm{CCl}_{4}$ & 26.5 & 327 & \\
\hline $\mathrm{N}_{2}$ & -195 & 342 & \\
\hline \multicolumn{4}{|c|}{ GEL No. 2} \\
\hline$n-\mathrm{C}_{6} \mathrm{H}_{14}$ & 26.5 & 342 & $\begin{array}{r}a=\text { BET nitrogen } \\
(355 \mathrm{~m} .2 / \mathrm{g} .)\end{array}$ \\
\hline $\mathrm{CCl}_{4}$ & 26.5 & 316 & \\
\hline $\mathrm{H}_{2} \mathrm{O}$ & 26 & 329 & \\
\hline \multicolumn{4}{|c|}{ GEL No. 3} \\
\hline $\mathrm{C}_{2} \mathrm{H}_{5} \mathrm{OH}$ & 45 & 477 & $\begin{array}{r}a=\text { BET nitrogen } \\
\left(455 \mathrm{~m}^{2} / \mathrm{g} .\right)\end{array}$ \\
\hline $\mathrm{H}_{2} \mathrm{O}$ & 26 & 433 & \\
\hline
\end{tabular}

method. Good agreement was also obtained between these values and the area obtained by dividing twice the liquid volume "adsorbed" at saturation by the dry radius of the capillary pores, i.e., $a=2 V_{S}$ /radius. (This dry radius was determined by adding the calculated multilayer thickness at the inception of capillary condensation to the radius calculated by the Kelvin equation using the $P / P^{0}$ value of the steepest point of the desorption curve.) For example, the "average" Kelvin radius for gel No. 1 was found to be $60.5 \mathrm{~A}$. and the multilayer thickness at the inception of capillary condensation in the average pore was calculated to be $9.8 \mathrm{~A}$. whence 
the dry radius was $70.3 \mathrm{~A}$. Since the average liquid volume at saturation was $1.17 \mathrm{cc} . / \mathrm{g}$., the area so calculated for gel No. 1 was $333 \mathrm{~m} .{ }^{2} / \mathrm{g}$.

\section{SUMmary}

1. Isothermals were obtained at $25^{\circ} \mathrm{C}$. for the adsorption of the vapors of methyl alcohol, ethyl alcohol, $n$-propyl alcohol, benzene, carbon tetrachloride, hexane, and water by silica gels of different apparent densities. For certain of these systems additional isotherms at 40 or $45^{\circ} \mathrm{C}$. were obtained.

2. The specific surface area of each gel was determined by three independent methods as follows: (a) by application of the BET equation to the low temperature nitrogen adsorption isotherms, (b) by the method based upon the assumption of the existence of uniform circular capillaries (i.e., $\left.a=\frac{2 V_{S}}{\text { radius }}\right)$, and (c) by treatment of the gravimetric data according to the free surface energy method of $\mathrm{Fu}$ and Bartell.

3 . For each system the values of the adhesion tension, work of adhesion, and initial spreading coefficient were calculated from the adsorption data by means of the Gibbs equation which interrelates surface area, surface tension, surface excess and chemical potential.

4. It was found that the free surface energy changes which occurred when unit areas of the different porous solids were replaced by unit areas of given solid-liquid or solid-saturated vapor interfaces were independent of the apparent densities of the adsorbent, i.e., the adhesion tension values calculated for a given liquid against a series of silica gels which differed in average pore radius, pore volume, and specific surface area were practically the same.

5. Inasmuch as six different organic liquids, possessing widely different surface tensions as well as widely different interaction energies against silica gave for a given gel similar values for surface area, which values were in good agreement with values obtained with other accepted methods, it appears justifiable to conclude that the free surface energy method of $\mathrm{Fu}$ and Bartell is generally applicable.

\section{REFERENCES}

1. Dobay, D., Fu, Y., and Barteld, F. E., J. Am. Chem. Soc. 73, 308 (1951).

2. Fu, Y., and Banteld, F. E., $J$. Phys. \& Colloid Chem. 55, 662 (1951).

3. Bartell, F. E., and Dobay, D., J. Am. Chem. Soc. 72, 4388 (1950).

4. Barteli, F. E., and Donahue, D. J., J. Phys. Chem. (in press).

5. Emme'Tt, P. H., Advances in Colloid Sci. 1, 1-36 (1942).

6. Barterl, F. E., ANo Dodd, C., J. Phys. \& Colloid Chem. 54, 114 (1950).

7. McBain, J. W., AND BAKR, A. M., J. Am. Chem. Soc. 48, 690 (1926).

8. Bangham, D. H., Trans. Faraday Soc. 33, 805 (1937).

9. Bangream, D. H., and Razouk, R. I., Trans. Faraday Soc. 33, 1459 (1937).

10. Bangham, D. H., and Razouk, R. I., Proc. Roy. Soc. London A166, 572 (1938). 
11. Boyd, G. E., ANd Livingston, H. K., J. Am. Chem. Soc. 64, 2383 (1942).

12. JuRa, G., and Harkins, W. D., J. Am. Chem. Soc. 66, 1356 (1944).

13. Barteli, F. E., and Merrild, E. J., J. Phys. Chem. 36, 1178 (1932).

14. Barteld, F. E., and Osterhof, H. J., J. Phys. Chem. 37, 543 (1933).

15. Barteli, F. E., and Whitney, C. E., J. Phys. Chem. 36, 3115 (1932).

16. Bartell, F. E., And Almy, E. G., J. Phys. Chem. 36, 475 (1932).

17. Barteli, F. E., AND Fu, Y., Colloid Symposium Annual. Seventh Colloid Symposium Monograph. John Wiley, New York, 1930, p. 135.

18. Patrick, W. A., ANd Grimm, F. E., J. Am. Chem. Soc. 43, 2144 (1921).

19. Boyd, G. E., ANd Harkins, W. D., J. Am. Chem. Soc. 64, 1190 (1942).

20. Bower, J. E., Thesis, Univ. of Michigan (1951).

21. Harkins, W. D., and Jura, G., J. Am. Chem. Soc. 66, 1362 (1944). 